\title{
Superficial Angiomyxoma of Index Finger: A Rare Entity
}

\author{
Swati Patki* and Pankaj Shah
}

Aspira Path lab \& Diagnostics Centre, Mumbai, India

\section{ABSTRACT}

Superficial acral angiomyxoma(SA) that is digital angiomyxoma is a rare tumor with a predilection for the subungual or periungual regions of the hands and feet. To date, fewer than 50 cases have been reported worldwide. The present case, hence, is unusual, because the lesion developed on the index finger. Histologically characterized by being poorly delimited tumors with the presence of interstitial scanty cellularity and myxoid material. We discuss the clinical and histological features of digital SA as well as a brief outline of other myxoid lesions.

\section{Keywords: Acral, Cutaneous Myxoma, Superficial Angiomyxomas}

\section{Introduction}

Superficial acral angiomyxoma (SA) is a rare, slow growing, solitary, soft tissue tumor, which was initially described in 2001. They are usually located on the trunk, but can also appear on the lower limbs, head, and neck. SA is a relatively new entity, most likely representing a fibrohistiocytic neoplasm..$^{[1]}$ They have only been infrequently described on the digit mimicking a digital myxoid cyst. Originally proposed to be synonymous with cutaneous focal mucinosis, trichofolliculomas and trichodiscomas. ${ }^{[2]}$

\section{Case report}

Here we present a case of 43 years old male who came with complaints of a red raised lesion on the left index finger since 1 year. The lesion had gradually increased to present size and tender to touch. There was no history of trauma or other skin lesions. We received a specimen of soft tissue tumour as multiple skin covered tissue bits aggregating to measure $2 \times 1 \times 1 \mathrm{~cm}$ and on cut surface had congested appearance . Histopathological examination revealed a dermal tumour composed of bland spindle and stellate cells arranged in a fascicular and storiform pattern against a myxoid and collagenous .The diagnosis of the superficial acral fibromyxoma was considered.

\section{Discussion}

Though first described in 1988, Superficial angiomyxoma(SA) is still a poorly recognized cutaneous tumor. It was first described and named as a cutaneous myxoma of Carney's complex by Carney et al. in 1986. In 1988, Allen et al. ${ }^{2}$ reported cutaneous tumors that were histologically similar to cutaneous myxomas of Carney's complex but had no evidence of the complex and named it SA (due to a predominant vascular component). Nearly 30 cases SA were reported in individuals whose age group ranged between 4 to 78 years and slight male predeliction was noted. The size of the tumour ranged between 1 to 5 $\mathrm{cm}$. Majority of the tumours were located over the trunk and head and neck region.,

SA usually present as solitary, locally recurrent and non metastatic tumour that occur most commonly in the third to fourth decade, as in our case. Histopathology reveals a poorly demarcated lesion characterized by myxoid stroma with mucin pools, bland spindle and stellate cells and prominent vascularization. Immunohistochemically negative for S100, SMA as well as muscle specific actin, with occasional positivity for CD34. Carney complex can be considered if there are multiple SA, especially those located over ear pinna and external ear along with other features of endocrine over activity. The differential diagnosis of a mucinous dermal nodule is vast and the list includes digital myxoid cyst and Cutaneous focal mucinosis .,4 Digital myxoid cyst is known to occur over distal interphalangeal (DIP) joint and histopathologically tend to show a well-circumscribed, large deposit of mucinous material associated with some fibroblasts in the upper to middle dermis, and there is usually no great degree of vascularity. Cutaneous focal mucinosis is largely acellular with very few blood cells, and it lacks a lobular architecture and stromal neutrophils, thus those findings do not correlate with the features observed in our patient's lesion. ${ }^{4}$

These tumours are characterized by local recurrence thus complete excision and follow-up review are 


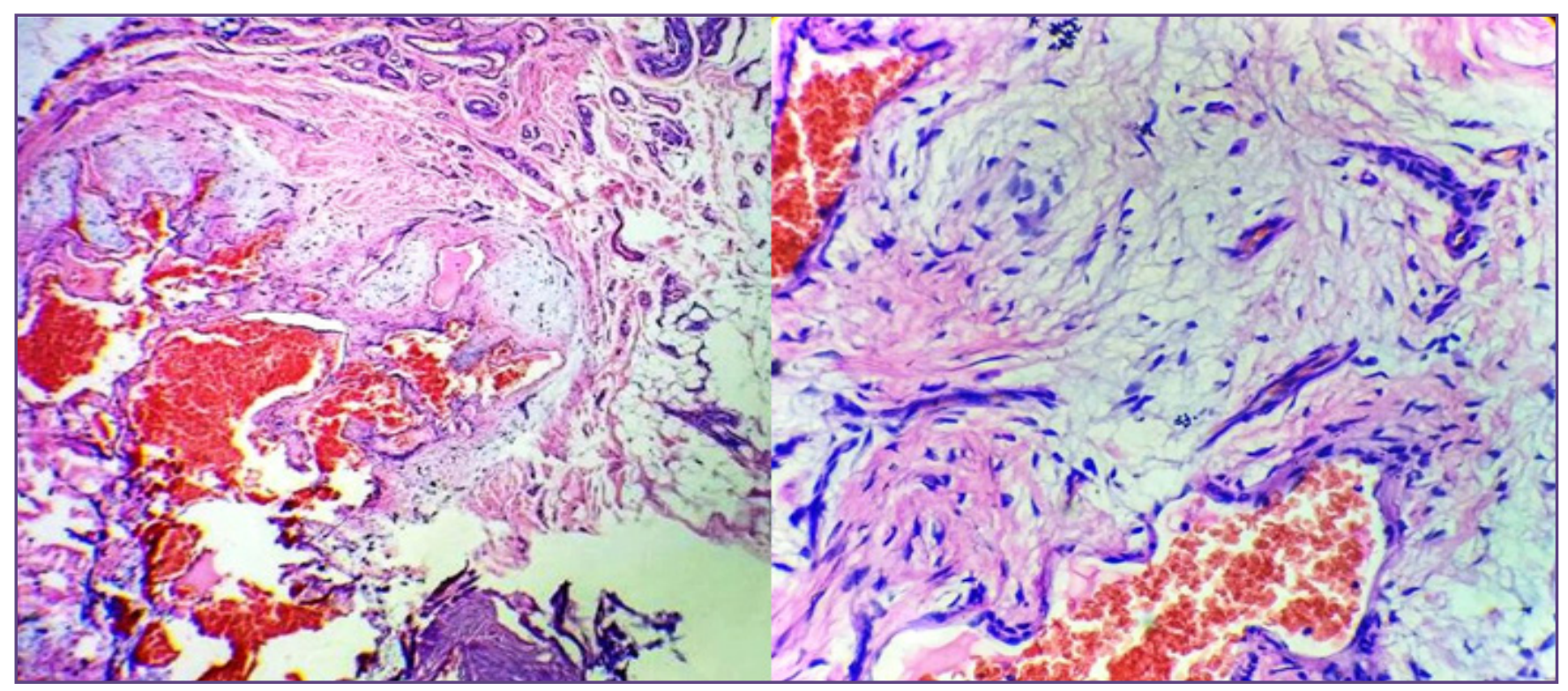

Fig. 1:Cutaneous angiomyxoma with bland spindle and stellate cells arranged in a fascicular and storiform pattern against a myxoid and collagenous alongwith thick and thin walled blood vessels.

recommended. Close follow up is also mandated since SA can represent the earliest and only manifestation of the Carney's syndrome. ${ }^{[5,6]}$

\section{Conclusion}

To summarize digital angiomyxoma is a distinct and rare, cutaneous spindle cell neoplasm with a striking predilection for the subungual or periungual region of the hands and feet. Digital angiomyxoma is a benign tumor with a propensity for local recurrence when incompletely excised. To date, metastasis has not been reported.

\section{References}

1. ura $\mathrm{M}$ M, Jindal $\mathrm{S}$ R. Solitary Superficial Acral Angiomyxoma: An Infrequently Reported Soft Tissue
Tumor .Indian Journal of Dermatology. 2012;3:24-27.

2. Allen PW, Dymock RB, MacCormac LB. Superficial angiomyxomas with and without epithelial components. Report of 30 tumors in 28 patients. Am J Surg Pathol. 1988;12:519-30.

3. Enzinger FM, Weiss SW. 3rd ed. St. Louis: Mosby - Year Book, Inc; 1995. Soft tissue tumors.

4. Andre, Theunis J, Richert A, Bertrand M et al. Superficial Acral Fibromyxoma: Clinical and Pathological Features. American Journal of Dermatopathology.2004; 26: 472-474

5. Arık D, Canaz F, Karabagh Y. Superficial Acral Fibromyxoma Erciyes Med J. 2014; 36: 181-3

6. Richardson H A, Rogers G S, ,Stadecker J M. Superficial Acral Fibromyxoma An Overview.Arch Pathol Lab Med. 2011;135:1064-1066
*Corresponding author:

Dr Swati Patki, \#63,A-202, Tilak Shanti Chs, Tilak Nagar Mumbai-89, India,

Phone: +91 8291026779

Email: drspkulkarni@yahoo.com

Financial or other Competing Interests: None.
Date of Submission : 18.08.2017

Date of Acceptance : 27.09.2017

Date of Publication : 13.01.2018 